\title{
Article \\ Mathematical Modeling and Simulation of Suspended Equipment Impact on Car Body Modes
}

\author{
Sunil Kumar Sharma ${ }^{1}\left({ }^{1}\right.$, Jaesun Lee ${ }^{2} \oplus$ and Hong-Lae Jang ${ }^{2, *}$ \\ 1 School of Engineering \& Applied Science, National Rail and Transportation Institute, \\ Vadodara 390004, Gujarat, India; sk.sharma@nrti.edu.in \\ 2 School of Mechanical Engineering, Changwon National University, Changwon 51140, Korea; \\ jaesun@changwon.ac.kr \\ * Correspondence: hjang@changwon.ac.kr; Tel.: +82-55-213-3623
}

check for updates

Citation: Sharma, S.K.; Lee, J.; Jang, H.-L. Mathematical Modeling and Simulation of Suspended Equipment Impact on Car Body Modes. Machines 2022, 10, 192. https://doi.org/ 10.3390/machines10030192

Academic Editors: Dimitrios Chronopoulos and Tzu-Kang Lin

Received: 20 January 2022

Accepted: 3 March 2022

Published: 6 March 2022

Publisher's Note: MDPI stays neutral with regard to jurisdictional claims in published maps and institutional affiliations.

Copyright: (c) 2022 by the authors. Licensee MDPI, Basel, Switzerland. This article is an open access article distributed under the terms and conditions of the Creative Commons Attribution (CC BY) license (https:// creativecommons.org/licenses/by/ $4.0 /)$.

\begin{abstract}
A passenger railway vehicle's lightweight design is an efficient technique of reducing energy consumption and dynamic forces between wheel and rail. However, light design results in resonant vibration in a car body. To restrain resonant vibration, a correlation between the suspended equipment variables and the car body's modal frequency was investigated in this paper. A rigidflexible general model was developed to examine the impacts of different equipment suspended under the chassis based on mass, location, and frequency on the car body mode. In addition, the numerical model is validated through the experimental result in terms of ride quality. The results demonstrate that the underframe equipment's suspension characteristics have a significant impact on the mode of the car body, particularly the frequency of the first bending mode. Equipment with a considerable mass should be suspended near the center of the car body to optimize the frequency of the car body's high-frequency bending. The weight of the equipment has a significant impact on the car body's first bending frequency. The frequency of heavy equipment should be low enough to promote high-frequency transmissibility and improve the vibration characteristics of the car body.
\end{abstract}

Keywords: suspended equipment; railway vehicle; rigid; flexible; vertical bending frequency

\section{Introduction}

With the rapid progress of high-speed rail vehicle technology, train operating speed is increasing while weight is decreasing to conserve energy. However, the high running speed expands the rail vehicle vibration frequency range and the light structure allows the flexible modes to be more easily triggered by wheel/rail interaction [1,2]. It was found that the car body (CB) vibration is more inflexible movement compared to rigid movement. Therefore, to create innovative technologies to enhance the dynamic response of rail vehicles at higher speeds, there is a need to understand the function of car body flexibility.

Considering that one of the most important design requirements for railway vehicles is weight reduction, which is necessitated by increased velocities, the need for reduced energy consumption, production costs, and the optimality of loads on the axle, the issue of $\mathrm{CB}$ structural flexibility is significantly vital. Reduced weight in the $\mathrm{CB}$ is frequently the result of decreased structural stiffness. The lighter the $\mathrm{CB}$, the more flexible it is, making structural vibrations in the $\mathrm{CB}$ easier to excite. $\mathrm{CB}$ fatigue is caused by structural vibration, which has an impact on the vehicle's service life and dynamic performance. However, the most noticeable influence of $\mathrm{CB}$ structural vibrations is shown in the ride comfort of the railway car body [3-9]. Within the frequency spectrum at which the human body has an extreme sensitivity to vibrations, eigen frequencies can be observed. More specifically, the first mode of $\mathrm{CB}$ vertical bending (VB), which occurs at a frequency of 6 to $12 \mathrm{~Hz}$, has the greatest impact on ride comfort. Several research frameworks have been undertaken in recent years in an attempt to find various techniques for improving the ride comfort by doing relevant research in improving flexible vibrations of the $\mathrm{CB}$ using active [10] 
or semi-active suspension system [11]. However, the vibration and wave propagation, including the damping of the rails that support the traveling axles, affect the rail wheel interaction force. As a result, these can cause real problems on railways, such as rolling noise and rail corrugation. Different generating mechanisms have been proposed for rail corrugation, depending on the corrugation's wavelength [12-16].

Manabe [17] established that rail VB mode and wave propagation are related to the growth mechanism of the rail corrugation with a medium wavelength of approximately $0.04 \mathrm{~m}$. It is typical of this type of rail corrugation that it can occur in straight lines as well. Many researchers have thus far contributed to the clarification of rail vibration modes. In particular, the relationship between short-pitch rail corrugation and pinned-pinned resonance at about $1 \mathrm{kHz}$ has been reported [18-23].

In addition, a wavelength fixing selection mechanism for rail corrugation due to the interference of rail vertical bending frequency (VBF) and lateral bending frequency (LBF) has been proposed. Most of these findings are based on theoretical analysis or numerical simulation. Many studies, such as rail wave propagation, are extensive. In the $\mathrm{CB}$ underframe, equipment such as pantograph compressors, traction converters, and traction transformers are located and weigh from tens of kilos to several tons and have their excitation source [24-26]. Hence, the suspended equipment design became a primary issue and research focus for enhancing the ride quality and safety, but also reducing energy consumption. Therefore, obtaining the optimum relationship between these underframes equipment with $C B$ vibration is still the attention of many researchers $[27,28]$.

Gong et al. [29] investigated the effect of the underframe suspended equipment on the CB flexible vibration by analyzing the relationship between the geometric filtering effect and the resonance frequency, and then proposed an optimized dynamic vibration absorber (DVA) to reduce the resonance. By evaluating the connection between the geometric filtering effectiveness and the resonance frequency, the influence of the underframe suspended equipment on the CB flexible vibration was examined, and an optimal DVA was developed to decrease the resonance. Shi et al. [20] developed a vehicle system dynamics model by integrating multibody-finite element technique dynamics theory to analyze the vibration response of the $\mathrm{CB}$ using suspended equipment. Huang et al. [23] used numerical modeling and actual experiments to inspect the effect of suspension variables on the vibration of CB and equipment. Sun et al. [30] created a 2-DOF DVA that can regulate the vehicle's low-frequency (LF) and high frequency (HF) vibration. On the other hand, mounting a dynamic vibration absorber (DVA) under the CB can reduce both the rigid and elastic vibrations of the $\mathrm{CB}$. The modal vibration can be reduced effectively by a suspended equipment with reasonably optimized suspension parameters, which works as a DVA. Both numerical analyses and field tests on a rig and on track verified that [22]. However, the vibration reduction measured in the field is less than that predicted by numerical simulations and lab tests because of restricted installation space and the limited mass and actual volume of the CBSE in operation. Consequently, CB modal vibration still arises on track, even when using vibration isolation and optimized suspension parameters based on DVA theory [22]

Dumitriu [19] used DVA theory to evaluate the impact of suspended equipment on human comfort using a vehicle model with no equipment and a model with the underframe equipment. At present, there are no generalized principles for designing the suspension parameters for the $\mathrm{CB}$ suspended equipment of a railway vehicle. Further consideration is required to determine the objective of vibration reduction, namely either the $\mathrm{CB}$ or the CB suspended equipment. Meanwhile, there has been no comprehensive study of how to classify the $C B$ suspended equipment or the corresponding parametric design methods. In the present investigation, the coupled vibrations between a flexible $\mathrm{CB}$ and its CB suspended equipment are studied by employing multi-body dynamics of a railway vehicle system, and the CB suspension parameters are analyzed. Moreover, a mathematical model is also used to investigate the effects of different equipment suspended under the chassis based on mass, location, and frequency on the CB mode. 


\section{Numerical Modeling}

The Link-Hofmann-Busch (LHB) coaches, India's fastest-moving rail coaches, are being evaluated for modelling and simulation. The rail vehicle's mathematical model includes the car body, two bogies, four-wheel sets, and suspended equipment (see Figures 1 and 2). These are linked by springs and dampers via suspension system [31]. A Euler-Bernoulli free-free type equivalent beam with constant section and equally distributed mass describes the car body. Many factors that affect the actual process of the flexible CB with bogie and wheelset are very complex. Therefore, the following reasonable assumptions should be made before establishing the mathematical model. i.e., in rigid-flexible coupled analysis, except for the $\mathrm{CB}$, the remaining parts, i.e., bogie and wheelset of a rail vehicle, are considered rigid bodies, each movement pair between the parts is a rigid connection, and the friction is generally not counted [32]. To evaluate the influence of the flexible components and obtain relatively accurate dynamic simulation results, the software of Solidworks and ANSYS was used to collaboratively model the rigid-flexible coupled co-simulation.

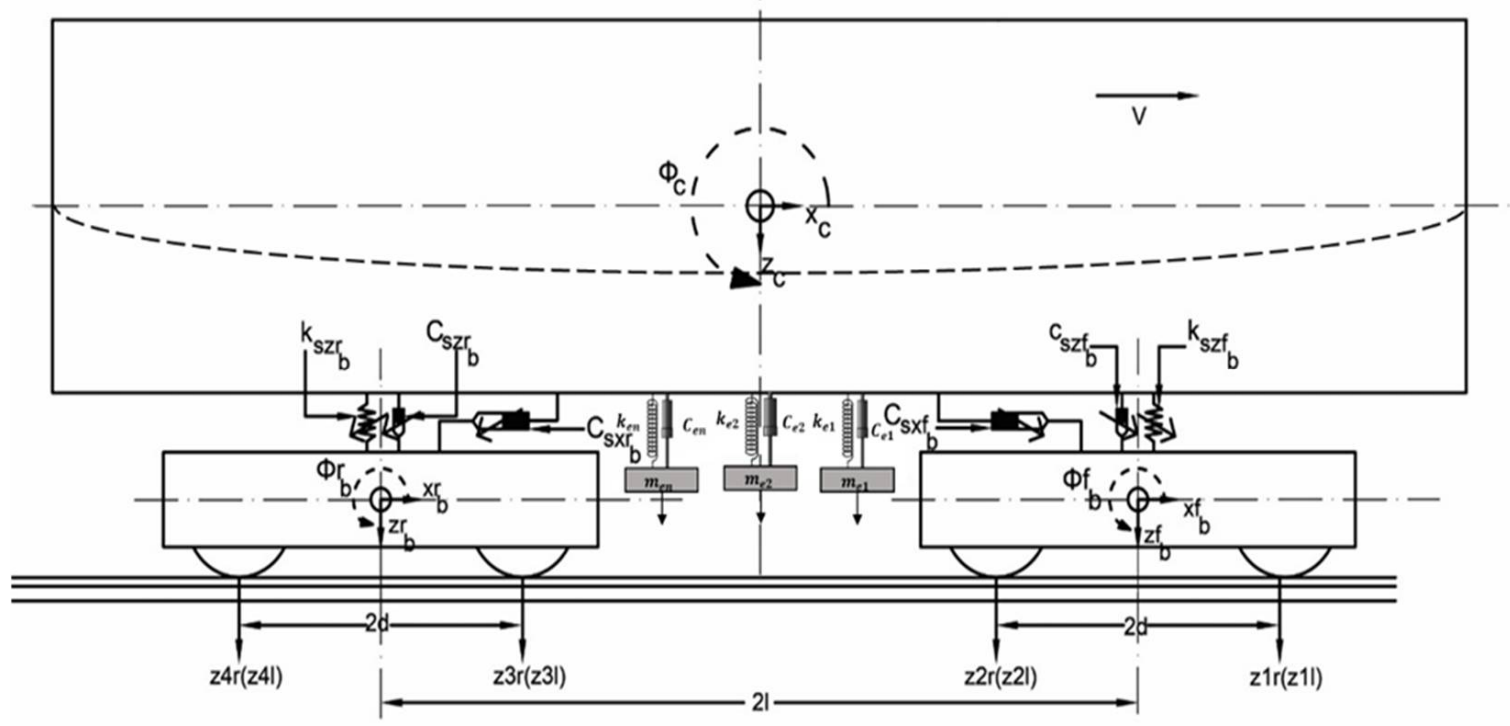

Figure 1. Schematic model of the passenger rail-vehicle LHB coach.

L(m)

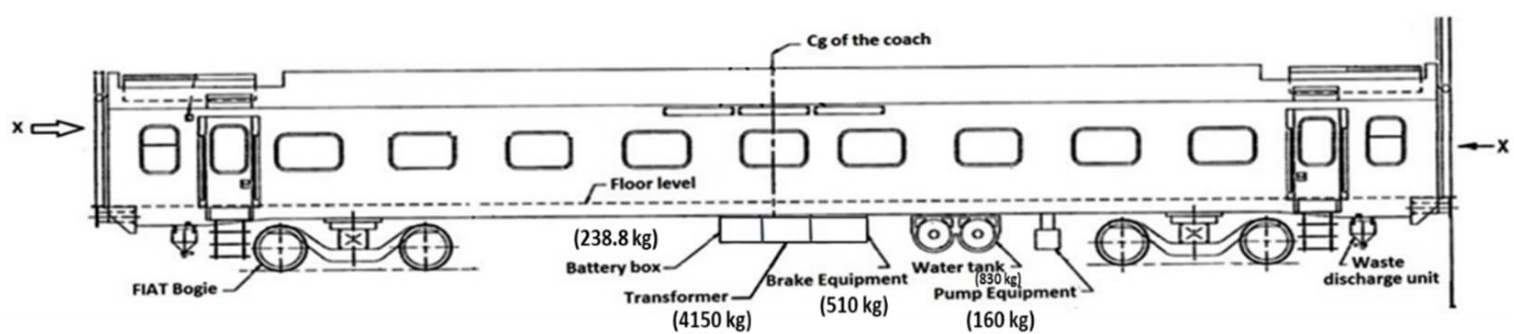

Figure 2. Schematic model of the passenger rail-vehicle with suspended equipment of LHB coach.

\subsection{Modeling of Flexible Car Body}

The car body parameters are defined in terms of the body of the vehicle, where $\mathrm{m}_{\mathrm{c}}$ : vehicle body mass and $E I$ bending modulus, where $E$ and $I$ denote the longitudinal elastic modulus and area moment of inertia for the beam's transversal section, respectively [21]. The bounce and pitch car body vibration modes, as well as the first car body bending 
eigenmode in a vertical plane, are considered, and the equation of motion for the general form is given in (Equation (1))

$$
\begin{aligned}
& E I \frac{\partial^{4} w_{c}(x, t)}{\partial x^{4}}+\mu I \frac{\partial^{5} w_{c}(x, t)}{\partial x^{4} \partial t}+\rho_{c} \frac{\partial^{2} w_{c}(x, t)}{\partial t^{2}} \\
& =\sum_{i=1}^{2} F_{c i} \delta\left(x-l_{i}\right)+\sum_{k=1}^{n} F_{e k} \delta\left(x-l_{e k}\right)
\end{aligned}
$$

where $\partial(x)$ is Dirac delta function; distance $l_{i}(i=1,2), F_{c i}$ stands for the forces derived from the secondary suspension corresponding to bogie $i$, and $F_{e k}$ represents the forces coming from the suspension of equipment (Equations (2) and (3)).

$$
\begin{gathered}
F_{c i}=-2 c_{c}\left(\frac{\partial w_{c}\left(l_{i}, t\right)}{\partial t}-\dot{z}_{b i}\right)-2 k_{c}\left(w_{c}\left(l_{i}, t\right)-z_{b i}\right) \\
F_{e k}=-2 c_{e k}\left(\frac{\partial w_{c}\left(l_{e k}, t\right)}{\partial t}-\dot{z}_{e}\right)-2 k_{e k}\left(w_{c}\left(l_{e k}, t\right)-z_{e k}\right)
\end{gathered}
$$

where $c_{\mathcal{c}}(0.035 \mathrm{MN}-\mathrm{sec} / \mathrm{m})$ and $k_{\mathcal{c}}(35 \mathrm{MN} / \mathrm{m})$ are the damping and stiffness coefficient of secondary suspension system [22]. The CB vertical movement $w_{\mathcal{c}}(x ; t)$ comes from the superposition of the two rigid vibration modes, namely bounce and pitch, with the first bending mode [21]:

$$
w_{\mathcal{c}}(x, t)=z_{\mathcal{c}}(t)+\left(x-\frac{L_{c}}{2}\right) \theta_{\mathcal{c}}(t)+X_{\mathcal{c}}(x) T_{\mathcal{c}}(t)
$$

where $T_{\mathcal{c}}(t)$ is the time coordinate of the first bending eigenmode in a vertical plan and $X_{c}(x)$ stands for its eigenfunction.

$$
X_{c}(x)=\sin \beta x+\sinh \beta x-\frac{\sin \beta L_{c}-\sinh \beta L_{c}}{\cos \beta L_{c}-\cosh \beta L_{c}}(\cos \beta x+\cosh \beta x)
$$

with $\beta=\sqrt[4]{w_{c}^{2} \rho_{c} /(E I)}$ and $\cos \beta L_{c} \cosh \beta L_{c}-1=0$.

When using the modal analysis approach and considering the eigenfunction's orthogonality property in the vertical bending of a vehicle body, Equation (1) becomes three two-order deferential equations with ordinary derivatives, representing the bounce, pitch, and bending movements in the CB.

$$
\begin{gathered}
m_{c} \ddot{z}_{c}=\sum_{i=1}^{2} F_{c i}+\sum_{k=1}^{n} F_{e k} \\
J_{c} \ddot{\theta}_{c}=\sum_{i=1}^{2} F_{c i}\left(l_{i}-\frac{L_{c}}{2}\right)+\sum_{k=1}^{n} F_{e k}\left(l_{e k}-\frac{L_{c}}{2}\right) \\
m_{m c} \ddot{T}_{c}+c_{m c} \dot{T}_{c}+k_{m c} T_{2}=\sum_{i=1}^{2} F_{c i} X_{c}\left(l_{i}\right)+\sum_{k=1}^{n} F_{e k} X_{c}\left(l_{e k}\right)
\end{gathered}
$$

where $m_{m c}, k_{m c}, c_{m c}$ are $\mathrm{CB}$ modal mass, damping, and stiffness, and are shown in Equation (9)

$$
k_{m c}=E I \int_{0}^{L}\left(\frac{d^{2} X_{c}}{d x^{2}}\right)^{2} d x, c_{m c}=\mu I \int_{0}^{L}\left(\frac{d^{2} X_{c}}{d x^{2}}\right)^{2} d x, m_{m c}=\rho_{c} \int_{0}^{L} X_{c}^{2} d x
$$




\subsection{Modeling of Bogies}

For each bogie, a vertical mode of vibration is considered as $z_{b i}$ with $i=1 ; 2$. The bogie pitch movement is neglected since it is not transmitted to the vehicle car body in this model. The equations of motion are given as

$$
\begin{aligned}
& m_{b} \ddot{z}_{b 1}=\sum_{j=1}^{2} F_{b j}-F_{c 1} \\
& m_{b} \ddot{z}_{b 2}=\sum_{j=3}^{4} F_{b j}-F_{c 2}
\end{aligned}
$$

where $F_{b j}$ stands for the forces coming from the primary suspension corresponding to axle $j$ as follows

$$
\begin{aligned}
& F_{b 1,2}=-2 c_{b}\left(\dot{z}_{b 1}-\dot{\eta}_{1,2}\right)-2 k_{b}\left(z_{b 1}-\eta_{1,2}\right) \text { for } j=1,2 \\
& F_{b 3,4}=-2 c_{b}\left(\dot{z}_{b 2}-\dot{\eta}_{3,4}\right)-2 k_{b}\left(z_{b 2}-\eta_{3,4}\right) \text { for } j=3,4
\end{aligned}
$$

where $c_{b}(0.0589 \mathrm{MN}-\mathrm{sec} / \mathrm{m})$ and $k_{b}(0.42375 \mathrm{MN} / \mathrm{m})$ are the damping and stiffness coefficient of primary suspension system. The suspended equipment has bounce movements that are described in Equation (14)

$$
m_{e k} \dot{z}_{e k}=-\sum_{k=1}^{n} F_{e k}
$$

The system equations can be written as the following

$$
M \ddot{p}+C \dot{p}+K p=P \ddot{\eta}+R \eta
$$

The inertia, damping, and stiffness matrices are $M, C$, and $K$, respectively, while the track displacement and velocity input matrices are $P$ and $R$. The kinematics of the $C B$ with the multiple suspended equipment are shown in Figure 2. The CB equations of motion are given in Equations (6)-(9) and the force acting on the CB from the suspension equipment is regarded as DVA and derived for each piece of suspended equipment given in Equation (16) and the specific position of action on the CB. Similarly, the equation of motion for each piece of suspended equipment is given in Equations (17)-(19).

$$
\begin{gathered}
F_{s e f, i}=-k_{e}\left[z\left(x_{s e f, i}, t\right)-z_{e} \pm \theta_{e} l_{e f, i}\right]-c_{e}\left[z\left(x_{s e f, i}, t\right)-z_{e} \pm \theta_{e} l_{e f, i}\right] \\
J_{c} \ddot{\theta}_{c}=\sum_{j=1}^{2} F_{s e j}(x-L / 2)+F_{s e f, i}\left(x_{s e f}-x_{e}\right) \\
m_{e} \ddot{\theta}_{e}=-F_{s e f, i}\left(x_{s e f, i}-x_{e}\right) \\
J_{c} \ddot{\theta}_{c}=F_{s e f, i}\left(x_{s e f}-x_{e}\right)
\end{gathered}
$$

where $k_{e}$ and $c_{e}$ are the stiffness and damping of the suspended equipment. Where $m_{e}$ and $J_{e}$ are the mass and moment of inertia, respectively, related to the CBSE pitching motion.

\section{Finite Element Analysis of Car Body}

\subsection{Finite Element Model of Car Body}

The passenger coach has been modeled using Solidworks and imported to ANSYS as shown in Figure 3. That computerized model is made up of substructures that are linked together to make a full vehicle. The various setups include both the front and rear bogies, along with the CB. From a structural dynamics point of view, these setups have 
been modeled as elastic bodies. All interconnections between substructures are defined independently. The wheelsets are not involved in the analysis since they are continually in contact with the track.

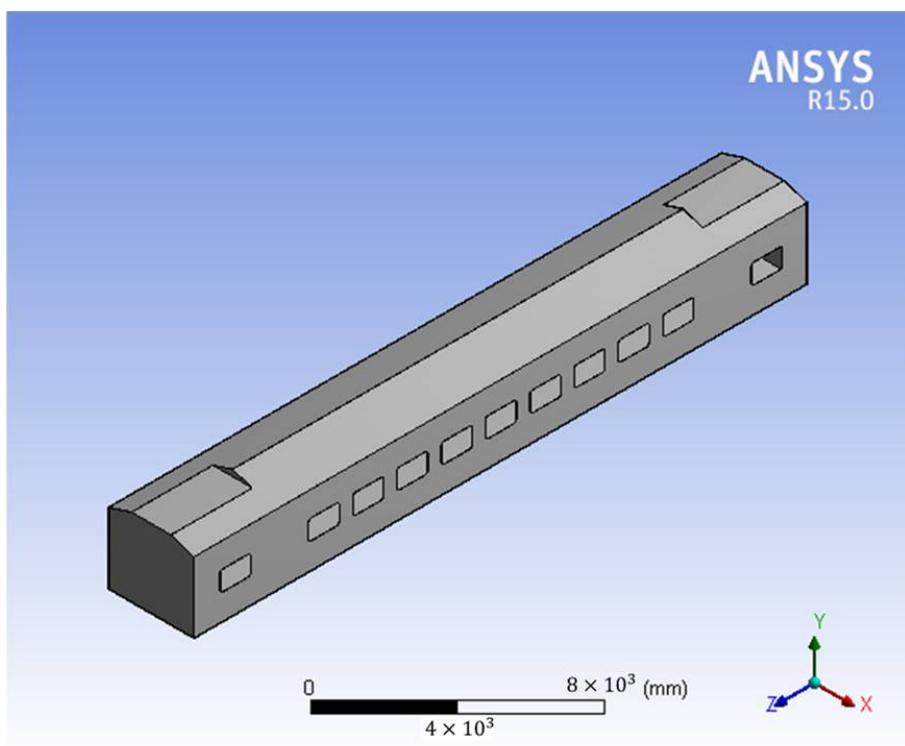

Figure 3. Model of the passenger railway LHB coach in ANSYS.

Considering the passenger coaches which were pivoted to bogies, the governing relationship between the $C B$ and suspended equipment under $C B$ chassis as a coupled system. As the main bearing structure suspended equipment was regarded as DVA, the CB mainly consists of the corrugated floor, side sill, underframe. A structural characteristic of grinders and plates could be simulated using the finite element analysis software. That analysis was carried out using ANSYS. The structure of CB was modeled employing a boxtype assembly consisting of beams and plates. The floor and roof were treated as orthotropic elastic plates which were simulated by shell and beam elements. A steel structure might be precisely replicated using these components. In the first case, a mass element was utilized to represent the counterweight. The equipment hanging from the underframe was replicated by weight at the center of mass, and the corresponding connection places were rigidly coupled. To be more precise, the model consists of the data listed in Table 1.

Table 1. FE model information.

$\begin{array}{ll}\text { Total Mass } & 32,253 \mathrm{~kg} \\ \text { Total Volume } & 4.1391 \times 10^{9} \mathrm{~mm}^{3} \\ \text { Total number of Nodes } & 59,8273 \\ \text { Total number of Elements } & 11,2477\end{array}$

\subsection{Modal Analysis of the Car Body}

Modal analysis is employed to solve the linear system's motion equations to find the system's natural frequency. Analytical approaches could not precisely govern the natural frequency due to the complicated construction of the CB. However, finite element methods might be used to solve it. The CB's motion equation is

$$
M \ddot{x}+C \dot{x}+K x=f
$$


where $M, C$, and $K$ represent the mass matrix, damping matrix, and stiffness matrix of the system, respectively. The loading vector is denoted by $f$, and the deformation shape vector is denoted by $x$ of the CB structure. The solution of the free vibration of the system, ignoring the structural damping on the modal frequency, is given by

$$
x=\delta \sin \left(\omega t+\varphi_{0}\right)
$$

where $\varphi_{0}$ and $\omega$ are the initial phase and circular eigen frequency, respectively, and $\delta$ is a magnitude vector. Now, Equations (20) and (21) seek non-zero solutions. For such solutions, Equation (22) gives eigenvalues and related eigenvectors, revealing the system's basic modes.

$$
\left|K-\omega^{2} M\right|=0
$$

\section{Validation of Numerical Modeling}

The numerical model in Section 2 is validated through the oscillation trial conducted by Research Design and Standards Organization (RDSO) on real conditions. The presented mathematical passive model's ride comfort for passengers is compared to the experimental results found by RDSO [33-35].

An on-track vibration test was designed and carried out to understand the vibration transition between the two suspension systems and the coupled vibrating between the car body and its suspended equipment. Accelerations on the wheelset axle-box, bogie frame, and connections between the car body and its suspended equipment were measured through accelerometers and displacement sensors connected to the data acquisitions system in the equipment cabin through cables. The on-track vibration test was designed for longterm and continuous vehicle dynamics recording. Based on the long-term dynamic's performance test for the prototype coach, the vibration characteristics of the equipment are analyzed. The lateral and vertical accelerations of the equipment and the car body under different bogie running performances are measured, and then the spectrum composition and the vibration source are analyzed. The rolling stock is driven at maximum speeds of $10 \%$ over operational speeds on a designated piece of Indian railway track. The oscillation tests were conducted on a well-maintained track at speeds ranging from 110 to $180 \mathrm{~km} / \mathrm{h}$. The sampling frequency of the frame acceleration is $2 \mathrm{kHz}$, and the passband frequency range is $0.5-12 \mathrm{~Hz}$. The sampling frequency of the equipment acceleration is $1 \mathrm{kHz}$, and the passband frequency range is $0.1 \sim 200 \mathrm{~Hz}$.

During oscillation testing, the maximum vertical and lateral ride index under empty and loaded situations were identified. The ORE C 116 technique [36] and the RDSO method [36] were used to determine the ride index. According to ORE C 116, the riding index should be between 2.75 and 3.25 (preferable) or 3.50 maximum as per RDSO requirements. The riding behavior of the same was found to be satisfactory.

The experimental and numerical riding indexes are compared in Figures 4 and 5 under empty and fully loaded situations, respectively. Furthermore, it can be observed that the numerical analysis of the suggested model yielded findings that were in good agreement with the experimentally measured data. The fluctuations in the ride index are mostly due to components not taken into account to reduce the complexity of the mathematical model. Moreover, it can be noticed that the values acquired from the proposed model demonstrate a better agreement with experimental values, with $6.36-10.61 \%$ error (lower) in case of loaded and $5.88-11.30 \%$ error (lower) in case of tare condition. 


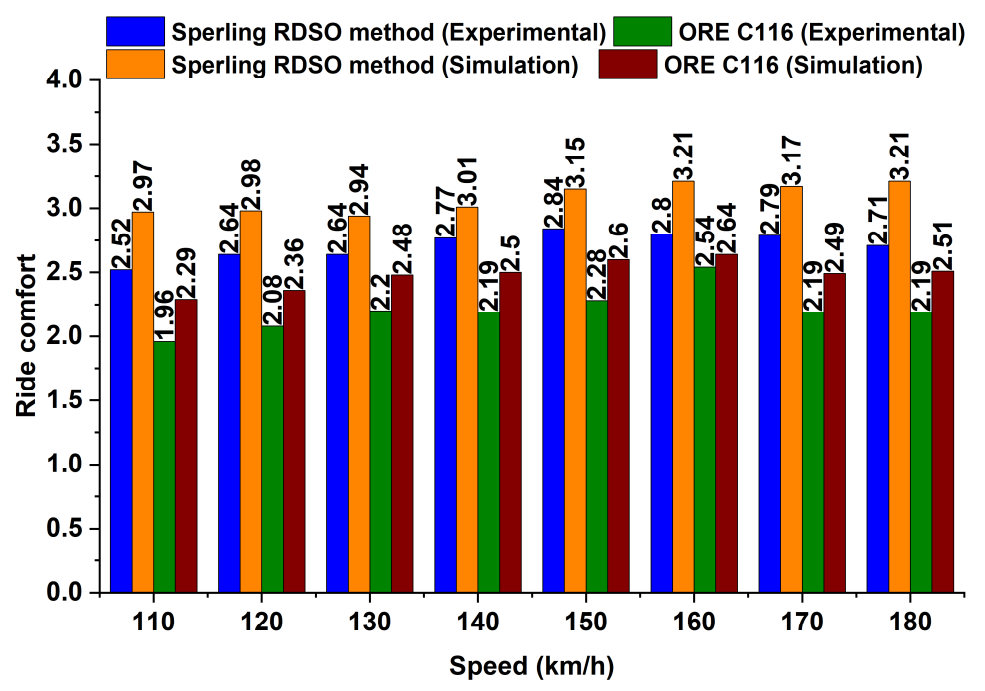

Figure 4. Comparison of numerical and experimental analysis for empty condition.

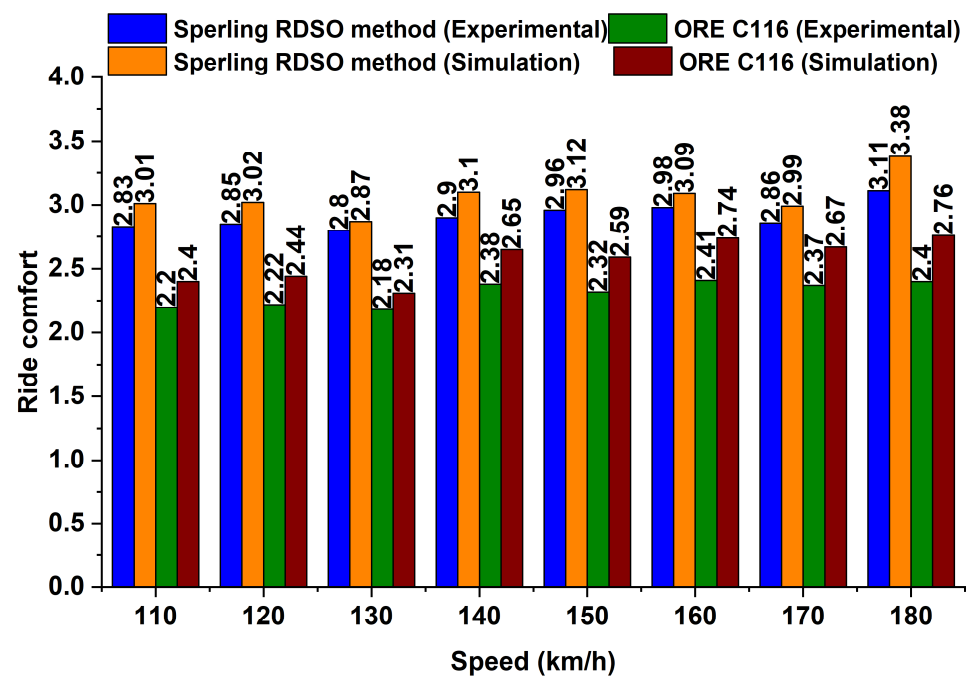

Figure 5. Comparison of numerical and experimental analysis for loaded condition.

\section{Result and Discussion}

A passenger rail vehicle $C B$ consists of different equipment suspended under the chassis, which consists of tons of kilograms. Hence, the relationship between suspended equipment and CB modes is developed. The finite element model is used to evaluate the mode of the CB and the mathematical model of vertical motion given in Section 2, for which the coupled system was considered to analyze the response of the system and the influence of suspended equipment parameters on the CB modes.

\subsection{Effect of Elastic and Rigid Suspended Equipment on Car Body Modal Frequency}

The modal frequency of the CB will be affected by suspended equipment. Hence, to develop the relationship, equipment considered as elastic and rigid and CB modes are evaluated. The comparison of modal frequency in terms of rigid and elastic car body consideration is shown in Table 2 and elastic modes are shown in Figure 6. 
Table 2. Comparison of modal frequency in terms of rigid and elastic car body.

\begin{tabular}{cccc}
\hline Mode Number & Mode Shape Description & Frequency (Hz) & Rigid \\
\hline & & 8.27 & Elastic \\
\hline 1 & Lateral swaying of sidewalls & 8.33 & 8.59 \\
3 & Rhombic mode or diagonal distortion & 13.50 & 8.98 \\
4 & Vertical bending mode & 15.10 & 14.32 \\
5 & Lateral shell breathing with rear and front walls swaying & 17.70 & 16.24 \\
6 & Lateral and rolling swaying at central length & 21.13 & 18.89 \\
7 & Torsion and longitudinal diagonal distortion of the front wall. & 24.05 & 23.47 \\
8 & Torsion and longitudinal diagonal distortion of the rear wall. & 26.54 \\
\hline
\end{tabular}

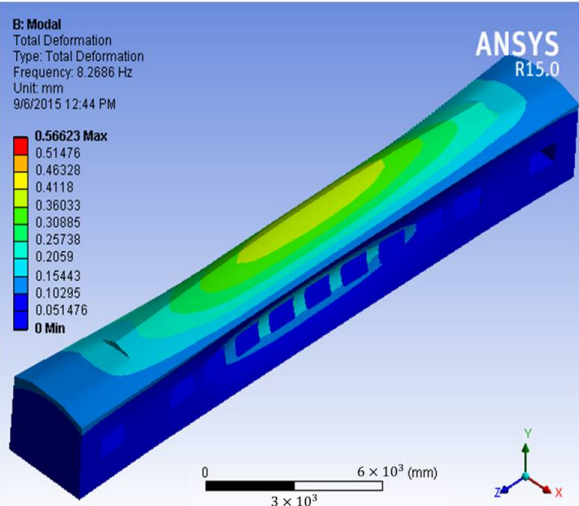

(a) first mode

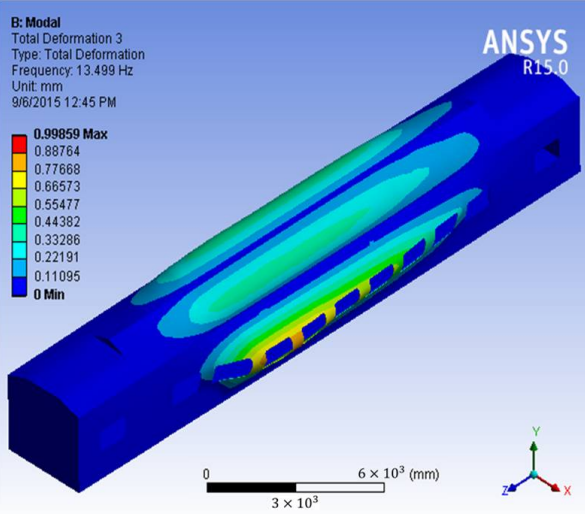

(c) third mode



(e) fifth mode

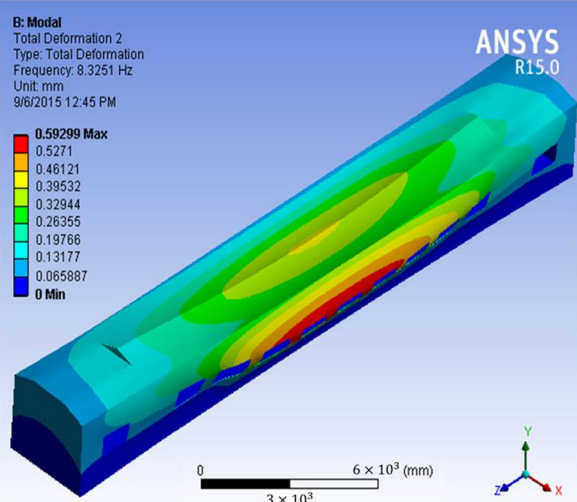

(b) Second mode

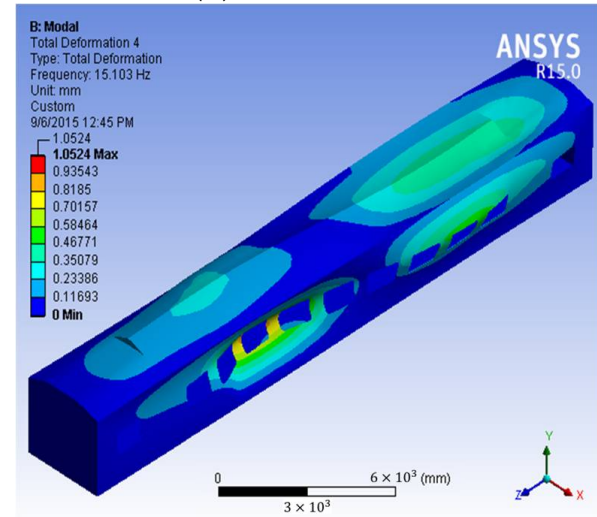

(d) fourth mode

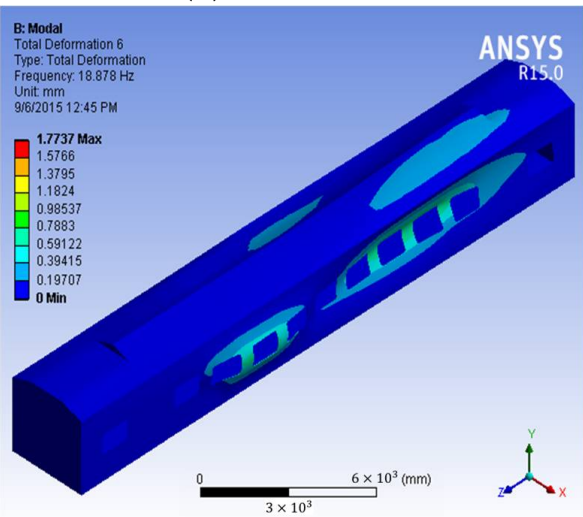

(f) sixth mode

Figure 6. Cont. 


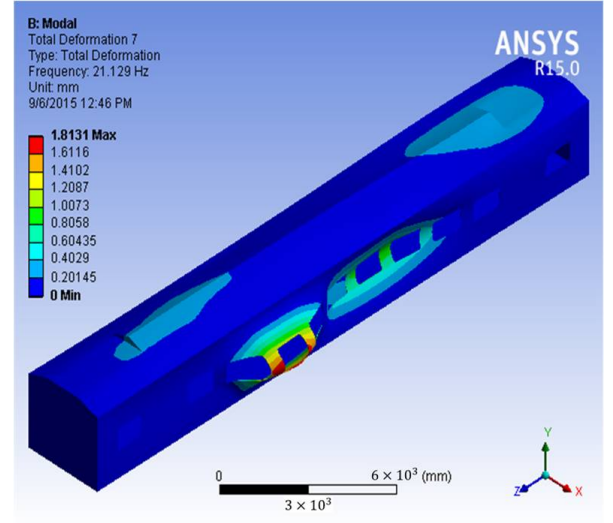

(g) seventh mode

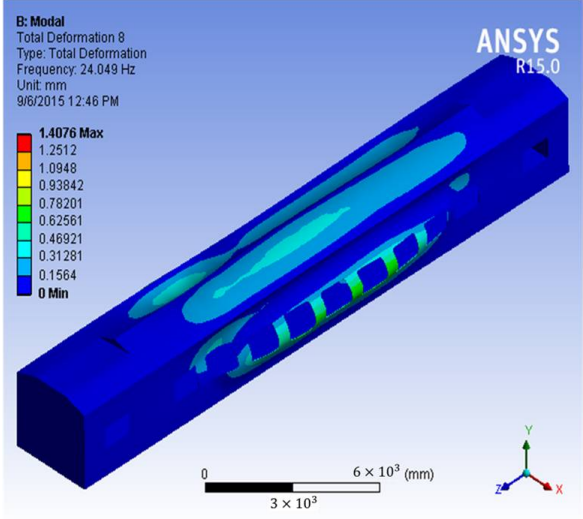

(h) eighth mode

Figure 6. Elastic flexural vibration mode at (a) $8.27 \mathrm{~Hz}$, (b) $8.33 \mathrm{~Hz}$, (c) $13.50 \mathrm{~Hz}$, (d) $15.10 \mathrm{~Hz}$, (e) $17.70 \mathrm{~Hz}$, (f) $18.88 \mathrm{~Hz}$, (g) $21.13 \mathrm{~Hz}$, and (h) $24.05 \mathrm{~Hz}$.

The comparison shows that the equipment parameter has a great effect on the first bending mode than the other mode, therefore for the analysis, other modes may be ignored. For elastically suspended equipment, LB and VB mode of 1st order appear. It is straightforward to establish that the LF mode is mostly created by bending movement in the $C B$ produced by the equipment's natural frequency, whereas the HF mode is primarily produced by the interaction between the $\mathrm{CB}^{\prime}$ 's natural frequency and the equipment using modal analysis. Elastically suspended equipment has a major impact on the 1st VB mode. One of the two new frequencies increases while the other lowers when compared to the $C B$ bending mode when considering the equipment as rigid suspension. The distance between the two new frequencies is proportional to the suspension parameters. Rigid suspension increases body weight while also shifting the mass center of the CB. Hence, there is only one VBF and one LBF. CB chassis has a certain kind of equipment suspended. Their masses and positions were different. Moreover, they are connected to $C B$ chassis via a rubber element whose property was discrepant for different equipment.

The location of the equipment on CB chassis is shown in Figure 2. Table 3 compares the original position of the equipment to that of the optimal location, and the assorted equipment's optimum suspension frequencies were calculated. The devices weigh about 4.15 ton to 0.16 ton, varying from the heaviest to the lightest. It was found that equipment suspension frequencies were close to the bending mode frequencies of a CB.

Table 3. Compares the original position of equipment to that of the optimal location.

\begin{tabular}{ccccccc}
\hline S.No & Equipment & Mass $\left(\mathbf{m}_{\mathbf{e}}\right) \mathbf{k g}$ & Mass Ratio $(\mathbf{u})$ & $\begin{array}{c}\text { Position } \mathbf{L}_{\mathbf{c}}(\mathbf{m}) \\
\text { Optimized }\end{array}$ & $\begin{array}{c}\text { Shape Function } \\
\mathbf{Y}_{\mathbf{1}}\left(\mathbf{L}_{\mathbf{c}}\right)\end{array}$ & $\begin{array}{c}\text { Frequency } \\
\text { Ratio } \mathbf{f}_{\mathbf{o p t}}\end{array}$ \\
\hline 1 & Waste discharge unit (I) & 70 & 0.002 & 22.27 & 0.73 & 1.00 \\
2 & Battery Box & 238.8 & 0.007 & 12.24 & -1.32 & 0.99 \\
3 & Transformer & 4150 & 0.129 & 11.79 & -1.32 & 0.82 \\
4 & Braking Unit & 510 & 0.016 & 10.61 & -1.26 & 0.98 \\
5 & Water Tank & 830 & 0.026 & 6.91 & -0.95 & 0.98 \\
6 & Pump Equipment & 160 & 0.005 & 8.53 & -0.55 & 1.00 \\
7 & Waste discharge unit (II) & 70 & 0.002 & 1.264 & 1.50 & 1.00 \\
\hline
\end{tabular}

\subsection{Effect of Suspended Equipment Location on Car Body Bending Frequency}

The effect of suspended equipment position, stiffness, and location on $\mathrm{CB}$ bending frequency for elastic and rigid suspended equipment are shown in Figures 7 and 8 . These results show that when the equipment position is near to the bogie, it is having the least impact on the different mode. A longer longitudinal distance between the bogie and the 
$\mathrm{CB}$ center indicates that the bending frequency with suspended equipment will be closer to the bending frequency without suspended equipment.
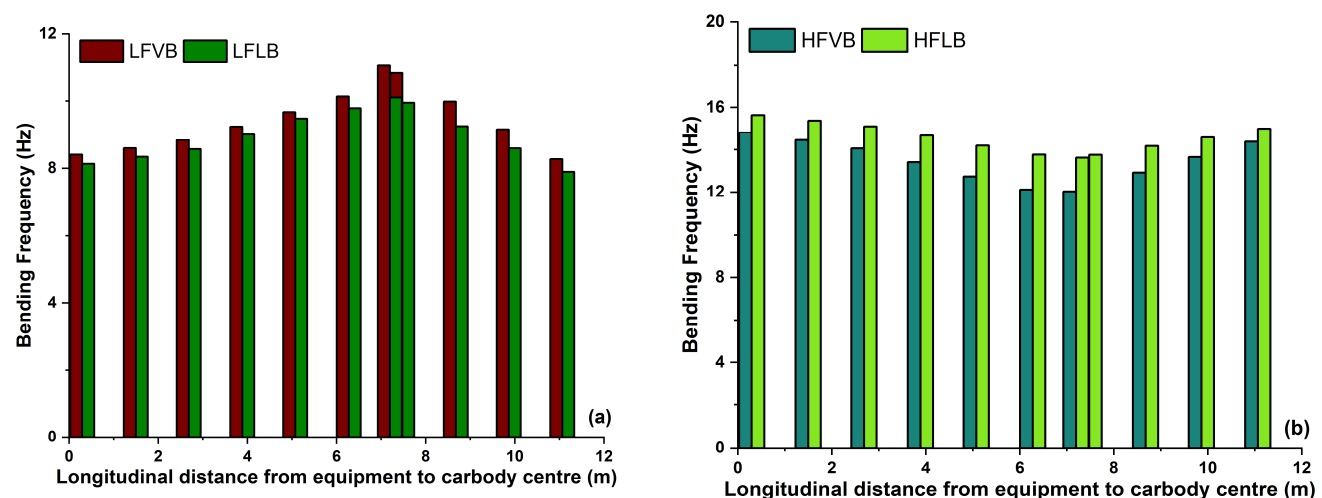

Figure 7. Association of bending frequency with the longitudinal distance from equipment to $C B$ center. (a) LFVB (b) HFVB for elastically suspended equipment.

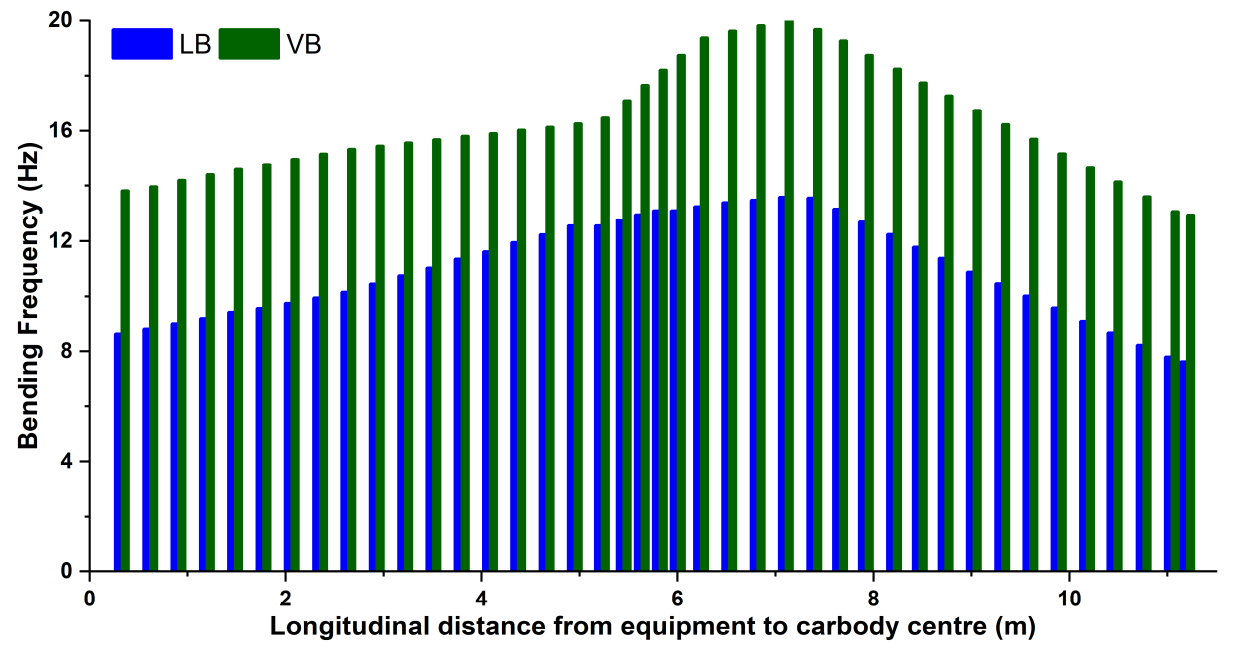

Figure 8. Association of $\mathrm{LBF}$ and $\mathrm{VBF}$ with the longitudinal distance from equipment to $\mathrm{CB}$ center for rigid suspended equipment.

When the longitudinal distance increases, the low-order coupled bending frequency increases, whereas the coupled frequency caused by the CB decreases. In the rigid suspension situation, there is just one bending frequency. It can also be seen that, when the equipment is suspended above the bogie, the modes are altered. Hence, suspended equipment would be suspended nearby the center of the CB because it improves the first-order bending frequency.

\subsection{Effect of Equipment Weight on Car Body Modes}

To develop the relationship of the equipment weight on VBF and transmissibility, a vertical track irregularity is considered in a vehicle model. Moreover, this analysis is done by keeping suspended equipment frequency constant to $13.50 \mathrm{~Hz}$ and maintaining suspension stiffness at $36.72 \mathrm{MN} / \mathrm{m}$. For suspended equipment frequency, the effect of equipment mass on VBF and transmissibility are shown in Figures 9 and 10. 

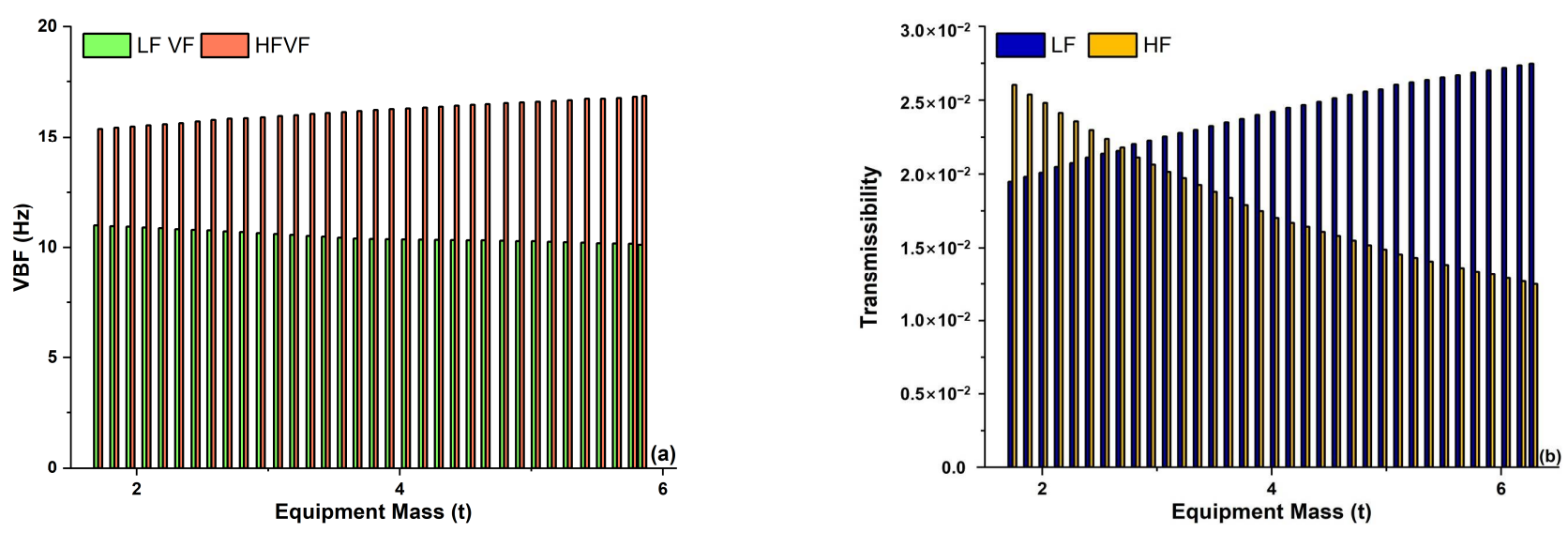

Figure 9. Effect of equipment mass on (a) VBF and (b) transmissibility for constant suspended equipment frequency.
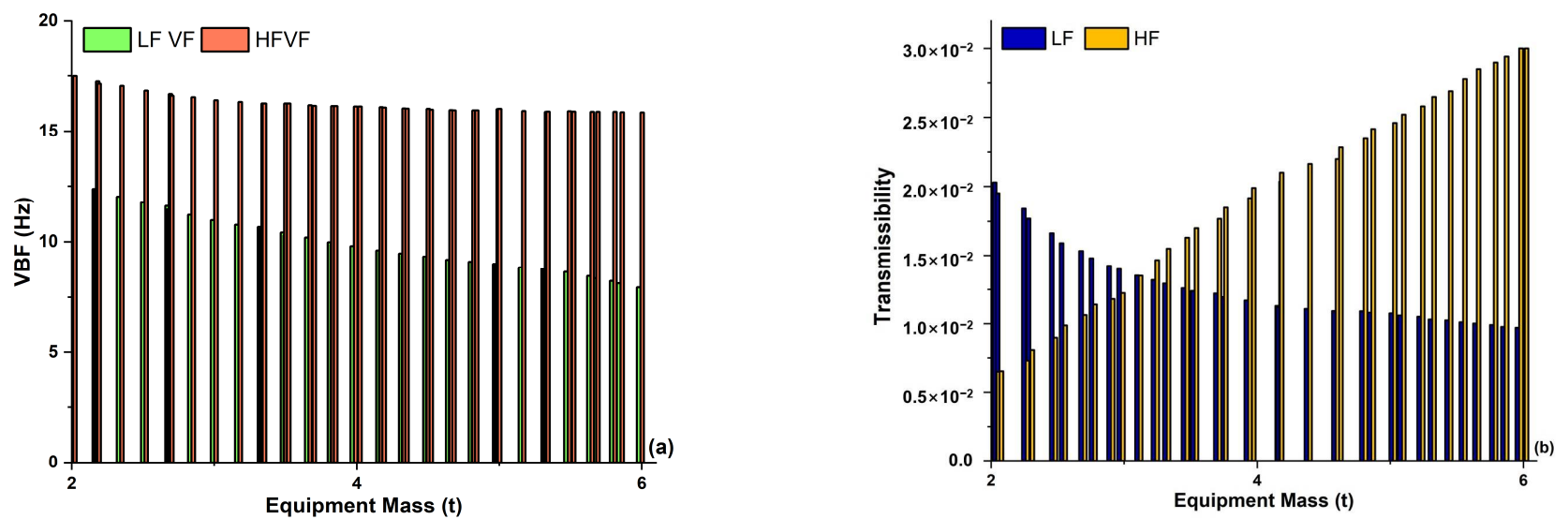

Figure 10. Effect of equipment mass on (a) VBF and (b) transmissibility for constant suspended equipment stiffness.

It can be observed that, when the equipment mass rises, the gap between high and low frequencies widens. As mass of equipment increases, the transmissibility of HF decreases, while that of LF increases. Similarly for maintaining suspension stiffness, the bending frequency of the $\mathrm{CB}$ steadily reduces as its mass increases. The shift in the LF component is more noticeable than the change in the high-frequency component. Simultaneously, high-frequency transmissibility increases while LF transmissibility decreases, reducing the sensitive frequency felt by passengers and improving ride quality. Therefore, the heavier the equipment, the smaller its suspension frequency should be to reduce the suspension stiffness of the equipment and increase the transmissibility of high frequencies.

\subsection{Effect of Suspension Equipment on Car Body Mode}

The effect of suspended equipment for rigid and elastic CB mode, i.e., transmissibility and VBF, are evaluated and shown in Figure 11a,b. The rigid suspended equipment is equal to increasing the mass of the $\mathrm{CB}$ without reducing its rigidity. This reduces the bending frequency of the 1st order while increasing transmissibility. As the suspension frequency rises, so does the bending frequency, and the low-order bending frequency approaches that of the absence of suspended equipment. The high-order bending frequency approaches infinity and finally equals the bending frequency under stiff suspension. However, when the suspension frequency changes, so does the transmissibility. When the suspension frequency is increased, the LF transmissibility increases, while the highfrequency transmissibility decreases. 

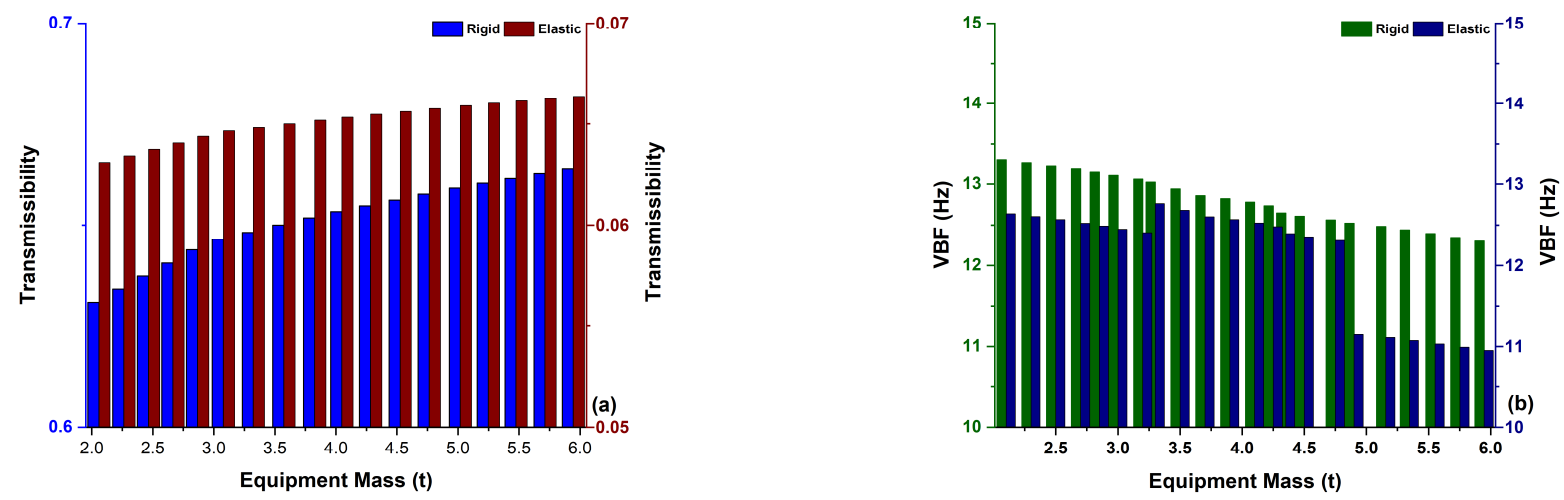

Figure 11. Rigid and elastic suspended equipment effect on $C B$ mode due to equipment mass (a) transmissibility (b) VBF.

\section{Conclusions}

In this paper, a generalized railway vehicle model is built to study the coupled vibrations between a flexible CB and its CBSE. In cases involving one piece of equipment, multiple pieces of equipment are introduced with specific equations of motion for general use. The associated theoretical basis for designing the CB suspended equipment parameters is then summarized systematically in DVA theory. The design principles suspension equipment parameters of rail vehicles are proposed. The mathematical model was used to investigate the impact of car body flexibility on the dynamics of a high-speed rail coach operating on a slab track. Moreover, a relationship is developed in terms of bending frequency and transmissibility between CB modes and suspended equipment. The FE Model is used to evaluate the mode of the $C B$ and the mathematical model was applied to study the effects of suspended equipment on the CB flexibility on the dynamic's performances of a rail vehicle. Moreover, the rigid flexible rail vehicle model was validated by experimental investigation. The mathematical model analysis shows that equipment with a considerable mass should be suspended near the center of the CB to optimize the frequency of high-frequency bending. The weight of the equipment has a significant impact on the first bending frequency. The CB suspended equipment is less than $1 \mathrm{t}$ and does not carry any excitation source, such as the brake unit, water tank, etc. Its suspension should be either stiff enough or a rigid connection to ensure connection reliability because it does not help reduce the $C B$ vibration. The equipment weighs $1-2 \mathrm{t}$ and does not carry any excitation source either, such as the battery storage near the CB end. Moreover, equipment weighs more than $2 \mathrm{t}$ and is not a source of excitation near the CB center, such as the transformer and converter. In that case, damped DVA theory should be used to determine its suspension frequency to reduce the CB structural vibration. The frequency of heavy hanging equipment should be low enough to promote high frequency transmissibility and improve vibration characteristics, and the frequency of suspended equipment should be lower than the bending frequency of the CB.

Author Contributions: S.K.S. prepared the inspection system for the experiment and performed the experiments presented in this research. J.L. conceived the original idea. H.-L.J. designed the methodology, gave guidance, and helped to improve the quality of the manuscript. S.K.S. wrote the original draft preparation in consultation with H.-L.J., who reviewed and edited the final manuscript. All authors have read and agreed to the published version of the manuscript.

Funding: This work was supported by a National Research Foundation of Korea (NRF) grant funded by the Korea government (MSIT) (No. 2019R1A5A808320112, No.2020R1G1A1011142).

Institutional Review Board Statement: Not applicable.

Informed Consent Statement: Not applicable.

Data Availability Statement: Not applicable. 
Conflicts of Interest: The authors declare no conflict of interest.

\section{References}

1. Smith, C.C.; Gilchrist, A.J.; Wormley, D.N. Multiple and Continuous Span Elevated Guideway-Vehicle Dynamic Performance. J. Dyn. Syst. Meas. Control 1975, 97, 30-40. [CrossRef]

2. Chen, C.; Wang, K. Study on modeling of lateral semi-active suspension system of high-speed train. J. Vib. Shock 2006, 25, 151-154.

3. Wu, Q.; Cole, C.; Spiryagin, M.; Chang, C.; Wei, W.; Ursulyak, L.; Shvets, A.; Murtaza, M.A.; Mirza, I.M.; Zhelieznov, K. Freight train air brake models. Int. J. Rail Transp. 2021, 1-49. [CrossRef]

4. Vishwakarma, P.N.; Mishra, P.; Sharma, S.K. Characterization of a magnetorheological fluid damper a review. Mater. Today Proc. 2021. [CrossRef]

5. Sharma, S.K.; Sharma, R.C.; Lee, J. Effect of Rail Vehicle-Track Coupled Dynamics on Fatigue Failure of Coil Spring in a Suspension System. Appl. Sci. 2021, 11, 2650. [CrossRef]

6. Bhardawaj, S.; Sharma, R.C.; Sharma, S.K.; Sharma, N. On the Planning and Construction of Railway Curved Track. Int. J. Veh. Struct. Syst. 2021, 13, 151-159. [CrossRef]

7. Sharma, R.C.; Sharma, S.; Sharma, N.; Sharma, S.K. Linear and Nonlinear Analysis of Ride and Stability of a Three-Wheeled Vehicle Subjected to Random and Bump Inputs Using Bond Graph and Simulink Methodology. SAE Int. J. Commer. Veh. 2021, 15, 65-79. [CrossRef]

8. Choi, S.; Lee, J.; Sharma, S.K. A Study on the Performance Evaluation of Hydraulic Tank Injectors. In Proceedings of the Advances in Engineering Design: Select Proceedings of FLAME 2020; Springer: Singapore, 2021; pp. 183-190.

9. Lee, J.; Han, J.; Sharma, S.K. Structural Analysis on the Separated and Integrated Differential Gear Case for the Weight Reduction. Adv. Eng. Des. Sel. Proc. FLAME 2020, 2021, 175.

10. Beltran-Carbajal, F.; Valderrabano-Gonzalez, A.; Favela-Contreras, A.; Hernandez-Avila, J.L.; Lopez-Garcia, I.; Tapia-Olvera, R. An Active Vehicle Suspension Control Approach with Electromagnetic and Hydraulic Actuators. Actuators 2019, 8, 35. [CrossRef]

11. Grzesikiewicz, W.; Makowski, M. Semi-Active System of Vehicle Vibration Damping. Appl. Sci. 2021, 11, 4577. [CrossRef]

12. Sharma, S.K.; Sharma, R.C.; Lee, J. In situ and experimental analysis of longitudinal load on carbody fatigue life using nonlinear damage accumulation. Int. J. Damage Mech. 2021. [CrossRef]

13. Sharma, S.K.; Lee, J. Crashworthiness Analysis for Structural Stability and Dynamics. Int. J. Struct. Stab. Dyn. 2021, 21, 2150039. [CrossRef]

14. Sharma, S.K.; Sharma, R.C. Multi-objective Design Optimization of Locomotive Nose. SAE Tech. Pap. 2021, 10. [CrossRef]

15. Sharma, R.C.; Palli, S.; Sharma, N.; Sharma, S.K. Ride Behaviour of a Four-wheel Vehicle using H Infinity Semi-active Suspension Control under Deterministic and Random Inputs. Int. J. Veh. Struct. Syst. 2021, 13, 234-237. [CrossRef]

16. Sharma, R.C.; Sharma, S.; Sharma, S.K.; Sharma, N.; Singh, G. Analysis of bio-dynamic model of seated human subject and optimization of the passenger ride comfort for three-wheel vehicle using random search technique. Proc. Inst. Mech. Eng. Part K J. Multi-Body Dyn. 2021, 235, 106-121. [CrossRef]

17. Manabe, K. A hypothesis on a wavelength fixing mechanism of rail corrugation. Proc. Inst. Mech. Eng. Part F J. Rail Rapid Transit 2000, 214, 21-26. [CrossRef]

18. Chen, J.; Wu, Y.; He, X.; Zhang, L.; Dong, S. Suspension parameter design of underframe equipment considering series stiffness of shock absorber. Adv. Mech. Eng. 2020, 12. [CrossRef]

19. Dumitriu, M. Influence of Suspended Equipment on the Carbody Vertical Vibration Behaviour of High-Speed Railway Vehicles. Arch. Mech. Eng. 2016, 63, 145-162. [CrossRef]

20. Shi, H.; Luo, R.; Wu, P.; Zeng, J.; Guo, J. Application of DVA theory in vibration reduction of carbody with suspended equipment for high-speed EMU. Sci. China Technol. Sci. 2014, 57, 1425-1438. [CrossRef]

21. Dumitriu, M. Numerical study of the inuence of suspended equipment on ride comfort in high-speed railway vehicles. Sci. Iran. 2020, 27, 1897-1915. [CrossRef]

22. Guo, J.; Shi, H.; Luo, R.; Wu, P. Parametric Analysis of the Car Body Suspended Equipment for Railway Vehicles Vibration Reduction. IEEE Access 2019, 7, 88116-88125. [CrossRef]

23. Huang, C.; Zeng, J.; Luo, G.; Shi, H. Numerical and experimental studies on the car body flexible vibration reduction due to the effect of car body-mounted equipment. Proc. Inst. Mech. Eng. Part F J. Rail Rapid Transit 2018, 232, 103-120. [CrossRef]

24. Sun, J.; Chi, M.; Jin, X.; Liang, S.; Wang, J.; Li, W. Experimental and numerical study on carbody hunting of electric locomotive induced by low wheel-rail contact conicity. Veh. Syst. Dyn. 2021, 59, 203-223. [CrossRef]

25. Sharma, S.K.; Kumar, A. The Impact of a Rigid-Flexible System on the Ride Quality of Passenger Bogies using a Flexible Carbody. In Proceedings of the Third International Conference on Railway Technology: Research Development and Maintenance, Stirlingshire, UK, 5-8 April 2016; Civil-Comp Press: Cagliari Sardinia, Italy; Stirlingshire, UK, 2016; p. 87.

26. Lu, Y.; Bi, W.; Zhang, X.; Zeng, J.; Chen, T.; Wu, P. Calculation method of dynamic loads spectrum and effects on fatigue damage of a full-scale carbody for high-speed trains. Veh. Syst. Dyn. 2020, 58, 1037-1056. [CrossRef]

27. Huang, C.; Zeng, J. Suppression of the flexible carbody resonance due to bogie instability by using a DVA suspended on the bogie frame. Veh. Syst. Dyn. 2021, 1-20. [CrossRef]

28. Sun, Y.; Zhou, J.; Gong, D.; Sun, W.; Xia, Z. A New Vibration Absorber Design for Under-Chassis Device of a High-Speed Train. Shock Vib. 2017, 2017. [CrossRef] 
29. Gong, D.; Zhou, J.S.; Sun, W.J. On the resonant vibration of a flexible railway car body and its suppression with a dynamic vibration absorber. JVC/J. Vib. Control 2013, 19, 649-657. [CrossRef]

30. Sun, Y.; Gong, D.; Zhou, J.; Sun, W.; Xia, Z. Low frequency vibration control of railway vehicles based on a high static low dynamic stiffness dynamic vibration absorber. Sci. China Technol. Sci. 2019, 62, 60-69. [CrossRef]

31. Sharma, S.K.; Kumar, A. Ride performance of a high speed rail vehicle using controlled semi active suspension system. Smart Mater. Struct. 2017, 26, 055026. [CrossRef]

32. Deng, Y.; Zhao, Y.; Xu, H.; Lin, F.; Wang, Q. Rigid-flexible coupling modelling and dynamic performance analysis of novel flexible road wheel. Proc. Inst. Mech. Eng. Part K J. Multi-body Dyn. 2020, 234, 67-81. [CrossRef]

33. Chandra, K. Maintenance Manual for BG Coaches of LHB Design; Centre for Advanced Maintance Technology: Gwalior, India, 2002.

34. Kumar, A. Oscillation Trails on LHB Coach (AC Chair Car) in Palwal-Mathura Section of Central Railway upto a Maximum Test Speed of 180 KMPH on Rajdhani Track Maintained to Strandards Laid Down; Research Designs and Standards Organisation: Lucknow, India, 2000.

35. Kumar, A. Operation of BG EOG Type LHB AC Chair Cars (LWFCZAC)E (LWSCZAC) Fitted with FIAT Bogies upto Maximum Speed of 160 Kmph on Track Maintained to CEM-1,Vol.-1 Standards on New Delhi-Palwal(Incl.) Section on UP E Dn lines of Northern Railway; Railway Board Ministry of Railways Government of India: New Delhi, India, 2015.

36. Singh, S. Analysis of Dynamic Behaviour of Existing Indian Railway Coaches and Possibilities of their Operation at $200 \mathrm{Kmph}$. Indian Railw. Tech. Bull. 2013, LXX, 1-13. 